\title{
A mediação tecnológica nos espaços educativos: uma perspectiva educomunicativa
}

Ismar de Oliveira Soares

Professor doutor e livre-docente do Departamento de Comunicações e Artes da Escola de Comunicações e Artes - ECA-USP.

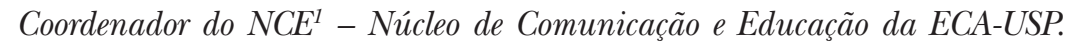

E-mail: ismarolive@yahoo.com

Os interesses dos usuários, especialmente jovens, ao cadastrarem-se na rede dos sites de relacionamento são os mais diversos, porém 80,99\% estão ingressando em busca de novos amigos, enquanto $27,19 \%$ procuram parceiros para diferentes atividades, relacionadas ao estudo, ao trabalho ou à cultura. Em média, a cada dez dias, um milhão de novos usuários - em sua maioria membros das gerações mais novas - ingressam no Orkut por meio de convites enviados por e-mail. Qual é o desafio que os sites de relacionamento representam para a educação? É possível ignorar a presença desta nova forma de expressão comunicativa?

A razão iluminista, própria da modernidade e responsável pela forma como se estruturou o ensino no mundo ocidental, encontra dificuldades, hoje, em oferecer paradigmas adequados para a construção de um projeto educativo que sirva às necessidades de definir e reafirmar as relações entre as representações e a realidade objetiva. Trata-se de uma razão instrumental e pragmática desafiada pelas dúvidas e incertezas do novo sujeito social. Deparamo-nos, então, com as demandas da pós-modernidade para as práticas educativas tradicionais².

Caracteriza-se, a pós-modernidade, pelo predomínio da técnica (o real converte-se em virtual, o que significa a concretização dos desejos e aspirações humanas traduzidos por sistemas digitais, através de programas) e da informação (os meios de comunicação produzem uma espécie de deshistorialização da experiência simbólica) ${ }^{3}$.

O desenvolvimento tecnológico permitiu, sem lugar para dúvidas, que a informação passasse a representar o fator-chave na oferta de bens e serviços, interferindo não somente na produção de bens de natureza material, mas, principalmente, naqueles de natureza simbólica. As tecnologias da informação constituem verdadeiramente um dos elementos mais dinâmicos da moderna economia mundial. Elas começam a expandir-se com a mesma violência das águas de um tsunami, penetrando e inundando tudo - os entretenimentos

1. <http://www/usp.br/ nce $>$.

2. DACAL ALONSO, José Antonio. Las grandes líneas: fuerzas que configuran el horizonte moderno (As grandes linhas: forças que configuram o horizonte moderno). Umbral XXI, México, n. 3. p. 18-19, 1996.

3. Ibid., p. 21. 
4. Ver sobre o tema: SOARES, Ismar de Oliveira. Sociedade da informação ou da comunicação. São Paulo: Cidade Nova, 1996; e DERTOUZOS, Michael. O que será? Como o novo mundo da informação transformará nossa vidas. São Paulo: Companhia das Letras, 1997.

5. <http://www.adusp.org. br>. Acesso em: 31 out. 2006. eletrônicos, a informação monopolizada e a educação a distância chegam igualmente a uma mansão, situada nas grandes cidades, assim como a uma cabana indígena, na aldeia de Sangradouro, no Mato Grosso -, interferindo no cotidiano de milhões de pessoas. Têm igualmente um grande impacto na organização do trabalho (fala-se no fim do emprego, tal como o concebemos no presente) e numa nova estratégia de poder mundial ${ }^{4}$.

Com a consolidação da Era da Informação, tudo se transforma rapidamente, desde as cosmovisões que alimentam o imaginário social até a forma como os seres humanos relacionam-se. Sem dúvida, para muitos, o impacto maior da nova condição civilizatória apresenta-se na maneira com que se move a economia da informação, especialmente na ausência crescente das certezas definidoras dos paradigmas que regiam as sociedades precedentes. E, embora ninguém esteja livre dessa avalanche de informações, não se pode dizer que suas conseqüências sejam sempre destrutivas. Até mesmo a educação faz parte desse cenário e recebe todas as influências transformadoras da revolução tecnológica. Da parte dos usuários, a maioria dos envolvidos pelos meios de comunicação digital - crianças e jovens, especialmente - gosta de conviver com as novas linguagens e os novos modos de produção e transmissão do conhecimento e sente-se confortável em relação ao seu uso, enquanto as gerações mais velhas ainda mantêm dúvidas, especialmente se o assunto é a educação formal ${ }^{5}$.

Em seminário ocorrido em Brasília, em outubro de 2006, especialistas convocados pela Andes e pela Associação dos Docentes da UnB apontaram, por exemplo, para os perigos do uso das tecnologias na educação, destacando, especialmente, os descaminhos do Ensino a Distância $(\mathrm{EaD})$ e suas implicações tanto nas práticas pedagógicas quanto nas políticas públicas de educação. Entre as questões levantadas, merecem destaque: 1) a confusão entre educação e ensino, sendo a educação um processo que promove a formação ampla dos indivíduos, enquanto o ensino é apenas o veículo por meio do qual se busca aumentar a chance de transmissão do conhecimento já consagrado e de construção de novos saberes, a partir de evidências fundamentadas de que alguns conhecimentos reclamam revisão criteriosa; 2) o perigo do $\mathrm{EaD}$ constituir uma porta aberta para a comercialização de pacotes educacionais, tratados inclusive como mercadoria transfronteiriça. De nossa parte, resta-nos acompanhar com atenção os que buscam apoderar-se dos novos recursos de forma criativa, capazes de construir um diálogo educativo mais próximo do cotidiano da comunidade educativa.

\section{CONSUMO DE MÍDIAS PELA JUVENTUDE}

O Brasil dá a impressão de ter entrado sem hesitações na Era da Informação, conforme comprovam dados recentes que apontam para uma adesão significativa, ao menos no campo da comunicação audiovisual: a população brasileira gasta, em média, 17 horas ouvindo rádio e 18,4 horas vendo TV, apresentando-se como a oitava no mundo em consumo de TV e a segunda no

consumo de rádio. É o que se pode verificar nos quadros adiante distribuídos 
pela NOP World Report Reports Worldwide - instituto que elabora rankings sobre comportamentos do mercado mundial de uso de mídia ${ }^{6}$.

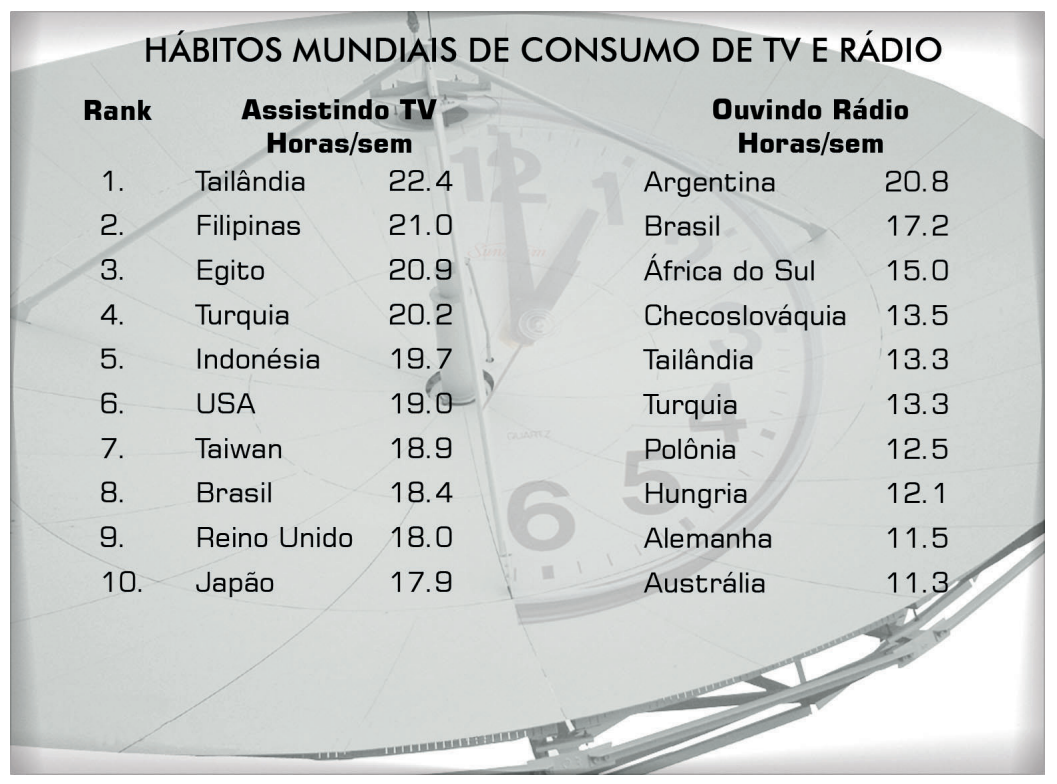

Cresce também o número de usuários da internet: a quantidade de pessoas que utilizam a web em suas casas aumentou, no Brasil, em 6,5\% somente entre fevereiro e março de 2006. O Ibope monitora diariamente os hábitos de navegação de cinco mil internautas, usando para tanto um software instalado nos computadores que permite a verificação dos sites acessados. Segundo estes dados, em março de 2006, os brasileiros ficaram em média 19 horas e 24 minutos conectados 7 . Já em maio, três meses depois, nota da Folha de S. Paulo informava que a média de uso diário da internet subira para 20 horas e 25 minutos, sendo que, no mesmo período, segundo um estudo do Ibope/Netratings, os franceses registraram média de 18 horas e 45 minutos, seguidos pelos japoneses ( 17 horas e 29 minutos) e americanos (16 horas e 45 minutos). Para se ter uma idéia do crescimento apresentado no Brasil, um ano antes, em maio de 2005, o tempo de navegação fora registrado em 16 horas e 55 minutos, o que representa um aumento de 3 horas e 30 minutos em apenas 12 meses $^{8}$.

Ainda com relação aos meios digitais, dados da empresa comScore Media Metrix informam que, no mundo todo, 694 milhões de pessoas acima de 15 anos navegam na internet, o que representa cerca de $14 \%$ da população total deste grupo etário. Desses quase 700 milhões, aproximadamente 14 milhões vivem no Brasil, colocando o país em 11ํ lugar no ranking dos usuários da internet ${ }^{9}$.

Um retrato do consumo brasileiro de internet no fim do século XX: entre os sites com maior número de usuários, o MSN, da Microsoft, lidera as preferências com 538,6 milhões de internautas, seguido de Google (495,8 milhões) e Yahoo (480,2 milhões) ${ }^{10}$. O Brasil, por sua vez, ocupa o segundo lugar entre os países no que se refere ao tempo de navegação na rede. Em maio de 2006, segundo o Ibope, o país apresentou um índice de conexão à rede apenas 4
6. <http://www.vivaleitura. com.br>. Acesso em: 24 maio 2006. A pesquisa foi realizada com mais de 30 mil pessoas acima de 13 anos de idade em 30 países, entre dezembro de 2004 e fevereiro de 2005.

7. <http://observatorio.ultimosegundo.ig.com.br/artigos.asp?cod=377ASP017> Acesso em: 25 out. 2006.

8. <http://www1.folha. uol.com.br/folha/informatica/ult124u20243.shtml> Acesso em: 2 nov. 2006.

9. <http://www.comscore. $\mathrm{com} / \mathrm{metrix} />$. Acesso em: 31 out. 2006.

10. <http://noticias.uol.com. br/ultnot/afp/2006/05/04/ ult1806u3815.jhtm>. Acesso em: maio 2006. 
11. <http://observatorio.ultimosegundo.ig.com.br/artigos.asp?cod=377ASP017 > Acesso em: 25 out. 2006.

12. <http://www.iprospect. com/premiumPDFs/WhitePaper_2006_SearchEngineUserBehavior.pdf $>$.

13. BARROS, Mariana. Internautas vão até 3 a página em resultados de buscas. Disponível em: <http://www1. folha.uol.com.br/folha/informatica/ult124u19912. shtml>.

14. ALVES, Marissol Mello. O uso da internet como instrumento de relacionamento: uma oportunidade para a aprendizagem. Trabalho de Conclusão de Curso de Pós-graduação lato sensu em Gestão de Processos Comunicacionais, Escola de Comunicações e Artes, Universidade de São Paulo, São Paulo, 2006. p. 19-21.

15. Ibid., p. 22-23. minutos menor do que a França, que registrou 19 horas e 28 minutos de uso diário da Rede Mundial de Computadores - um recorde também para aquele país. Com freqüência, os internautas brasileiros lideram esse ranking que contabiliza e compara o tempo de conexão e navegação em 11 diferentes nações, entre as quais os Estados Unidos e o Japão ${ }^{11}$.

Como a internet integra as mais diferentes mídias e as mais diversas linguagens, da escrita à audiovisual, podemos dizer que o brasileiro conectado à internet não busca apenas a leitura de textos, como o fariam os consumidores de livros, mas está atrás de diferentes informações em diversos suportes e linguagens. Os usuários estão optando por novos modos de perceber e de relacionar-se com o mundo e as pessoas ao seu redor. De acordo com um estudo das empresas de pesquisa Jupiter Research e iProspect ${ }^{12}$, apesar do aumento no uso da internet para buscas, os internautas não costumam, contudo, ultrapassar a terceira página em cada uma de suas visitas. Nesse sentido, figurar entre os primeiros links apresentados em uma pesquisa é algo valioso. Ainda mais quando 36\% dos internautas acreditam que as companhias que aparecem em primeiro lugar representam as principais marcas do mercado. Quando não encontram o que procuram, os usuários tendem a usar outro mecanismo de busca ou mudar a palavra-chave. Os que fornecem mais termos para aprimorar a pesquisa são minoria ${ }^{13}$.

O brasileiro - sobretudo o jovem - quer participar ativamente de novas comunidades virtuais destinadas ao lazer e ao relacionamento. As pesquisas mostram, por outro lado, que essas comunidades - formadas por sites de relacionamento, blogs e fotologs, entre outros - são os espaços virtuais que mais atenção recebem de seus usuários. Quanto às ferramentas mais populares, usadas para facilitar a comunicação interpessoal, aparecem o Messenger, da Microsoft, e a rede de relacionamento Orkut, do Google.

O MSN Messenger é atualmente o software de comunicação instantânea mais utilizado pelos internautas, liderando a categoria, com $68 \%$ de penetração. Atualmente na versão 7.5, o Messenger já não é mais visto apenas como um programa de bate-papo, mas até mesmo como ferramenta interativa dentro do sisudo contexto coorporativo. O Messenger é usado predominantemente pelo público masculino (57\%) e pelos jovens ( $54 \%$ dos usuários têm menos de 24 anos). Para utilizar o serviço é preciso ter uma conta MSN Passport. Quem tem a conta pode baixar o programa de fácil instalação no site da Microsoft (portal MSN) ou nos diversos sites de download gratuitos existentes na web. Interessante citar que o serviço, de tão popular, acabou abrindo oportunidade para a criação de diversos outros sites que disponibilizam on-line acessórios para os usuários do Messenger, como figuras para adicionar à galeria de emoticons (símbolos que ilustram emoções de quem digita), animações, fotos e sons ${ }^{14}$.

Com relação ao Orkut, os números são igualmente expressivos. Trata-se de uma rede social filiada ao Google, criada em 22 de janeiro de 2004 por Orkut Büyükkokten, jovem engenheiro turco a serviço da companhia, tendo como objetivo promover amizades virtuais e manter relacionamentos on-line. O sistema possui atualmente 18 milhões de usuários cadastrados. O Brasil é o país com o maior número de membros, aproximadamente 13 milhões - ou seja, $70,81 \%$ de usuários -, superando inclusive os EUA, com $11,90 \%$ dos internautas conectados a ele, o que equivale a cerca de 2 milhões de usuários $^{15}$. 


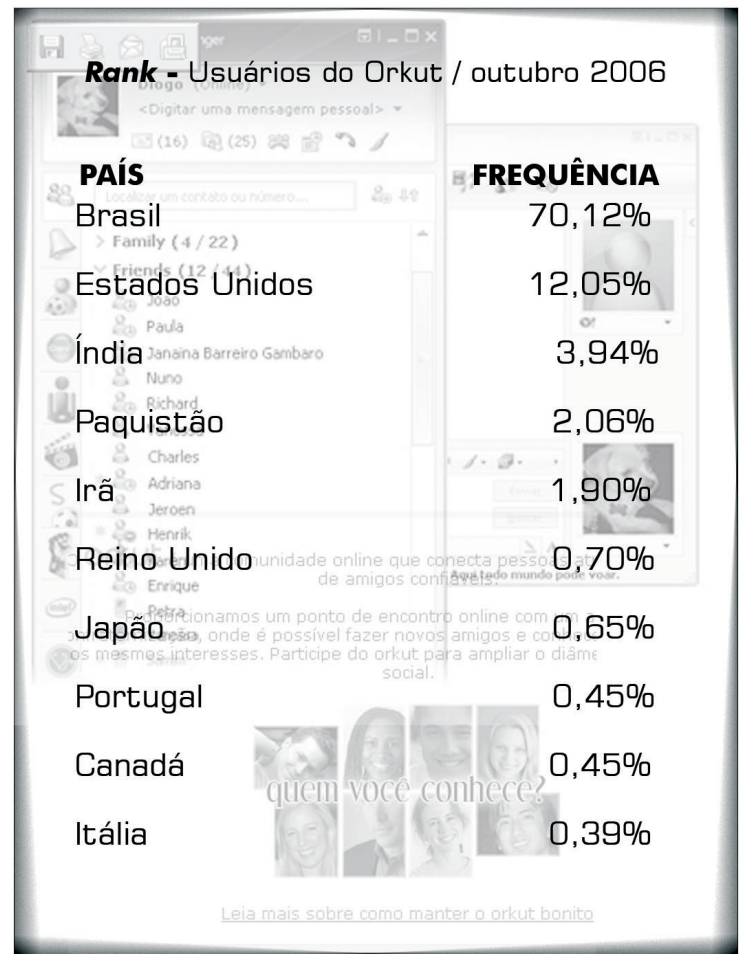

A adesão a essas ferramentas é atribuída ao fato de que as novas gerações nasceram em um mundo digital e têm interesses diversificados e multifacetados. Como eles próprios, esses programas são velozes, interativos e de fácil acesso.

São muitos os motivos e interesses dos usuários, especialmente jovens, ao cadastrarem-se numa rede como a do Orkut ${ }^{16}$. Segundo pesquisas elaboradas por nós em sala de aula, $80 \%$ dos jovens estão procurando fazer novos amigos, enquanto $30 \%$ buscam parceiros para diferentes atividades, que vão dos jogos ao namoro. O Orkut tornou-se tão popular no Brasil que já influencia a rotina das pessoas com vocabulário próprio:

- Orkutar: verbo utilizado pelos brasileiros para designar o ato de acessar o site Orkut.

- Scraps: palavra que significa recados. Cada perfil de usuário conta com uma página de comentários individual como forma de interação entre os usuários.

- ScrapChat: ocorre com a concentração de várias pessoas no ScrapBook de um certo indivíduo para bater papo, assim aumentando seus scraps no Orkut.

- Fã: você pode se declarar fã de quem você quiser, o mesmo acontecendo com os outros. A cada fã, uma estrelinha amarela aparece. Algumas vezes, o usuário acaba tendo fãs que nem mesmo conhece - tudo num esforço de conseguir a reciprocidade e obter a tão almejada popularidade virtual.

Analisando esses dados, é importante reconhecer que a liberdade que experimentam ao inserir seus posts (como são chamadas as mensagens enviadas em resposta a cada tópico) e interagir sem qualquer controle externo ou

16. Ver: <http://www.orkut. com>. O que há de novo: <http://www.orkut.com/ MembersAll.aspx>. 
compromisso com sua verdadeira identidade é o que mais agrada os membros das comunidades. Redes sociais já são responsáveis pela maior parte do tráfego na web. Em julho de 2006, por exemplo, o Orkut teve 9,6 bilhões de page views, demonstrando ser o site com o maior número de páginas vistas da web no Brasil. Apesar de sua popularidade, existem alternativas à rede social da Google.

- MySpace: é a rede com mais usuários no mundo, mais de 40 milhões. O seu principal diferencial é permitir a publicação de músicas, vídeos e a personalização completa do layout da página. Possui mais de 300 mil bandas e músicos como usuários. Voltada para o público jovem.

- Yahoo $360^{\circ}$ : sua principal característica é a integração com outros serviços da Yahoo! (e-mail, favoritos on-line, fotos). Lançada em março 2005, fornece blog, álbum de fotos e serviços de mensagens.

- Friendster: a mais antiga das redes sociais, fundada em 2002, nos EUA. Recentemente, recebeu um investimento de US\$ 10 milhões para sua expansão no exterior. É focado mais no público de 20 a 30 anos de idade.

- Multiply: lançada em 2003, permite o compartilhamento de fotos, textos e vídeos. Usuários podem ter seu jornal on-line e restringir o acesso aos seus perfis e comentários. Devido a sua complexidade de configuração, não foi bem recebida no Brasil.

- LinkedIn: com 6 milhões de usuários, é voltada para negócios e busca de empregos. Empresas e funcionários cadastram-se para trocar informações e aumentar sua lista de contatos. Algumas empresas de RH, nos EUA, usam a rede para selecionar funcionários.

- UOL K: a rede social mais nova no Brasil, foi lançada pelo portal UOL em novembro de 2005. Permite manter relacionamentos em segredo, pois o usuário determina o que será ou não exibido aos demais usuários da rede. Outro diferencial é a lista de contatos que é exibida em ordem alfabética $^{17}$.

\section{REAÇÕES ADVERSAS}

A constatação de que se amplia a adesão das novas gerações à ludicidade propiciada pelas tecnologias digitais preocupa, contudo, pais, psicólogos e, até mesmo, as autoridades policiais. Em 2 de setembro de 2006, o jornal $O$ Globo, baseado em dados da ONG Safernet ${ }^{18}$, informava, por exemplo, que a Polícia Federal ameaçava fechar o escritório da Google no Brasil, em decorrência de 34.715 denúncias sobre o uso do Orkut para difundir pornografia infantil, incluindo 40 mil imagens, envolvendo 1.202 grupos da comunidade virtual. No dia 22 de agosto de 2006, o Ministério Público Federal entrou com uma Ação Civil Pública exigindo que o Google Brasil fornecesse dados sobre usuários de comunidades que praticavam crimes no Orkut. O MP determinou que o escritório brasileiro quebrasse o sigilo de comunidades e perfis criminosos no Orkut e ajuizou uma ação para obrigar o Google Brasil a pagar multa diária de R \$,6 milhões e indenização por dano moral coletivo no valor de R\$ 130 
milhões, sob a alegação de que a empresa vem descumprindo, reiteradamente, decisões da Justiça brasileira. Em decorrência da pressão das autoridades, o Orkut publicou aviso aos usuários sobre atos ilegais. De acordo com o aviso, presente em todos os perfis de usuários, a empresa pedia que o internauta denunciasse comunidades e perfis com conteúdo ilegal. A nota dizia ainda que conteúdo ilegal não seria tolerado, sendo imediatamente removido pela equipe administradora do site. Na verdade, o aviso aos usuários apareceu depois de uma semana conturbada para o Orkut no Brasil, em que a representação brasileira do Google e o Ministério Público Federal de São Paulo iniciaram uma batalha judicial em torno de acusações de crimes como a disseminação de imagens de pedofilia. Enquanto isso, a revista eletrônica Fantástico, da Globo, em sua edição de 3/9/2006, mostrava aos seus 80 milhões de telespectadores os perigos da internet, documentando como um aparentemente pacífico e dedicado professor de educação física aliciava menores.

Se não é a pornografia, é o tempo gasto pelos usuários que trazem má fama à recém-instalada internet. Nesse sentido, a revista Isto é Online, de 26/4/2006, comenta:

A febre do MSN, o software de comunicação instantânea da Microsoft, atinge 16 milhões de usuários no Brasil. Junto a ela, alastra-se a preocupação com os prejuízos causados pelo excesso de tempo gasto com os bate-papos virtuais em ambientes de trabalho e estudo. Em várias empresas, o uso do MSN tem sido controlado. Em outras, foi simplesmente proibido ${ }^{19}$.

No campo da educação, as preocupações são semelhantes. Muitas escolas e faculdades vetaram o acesso ao MSN em suas dependências com a intenção de garantir a concentração dos alunos nos trabalhos didáticos, atenuando a dispersão promovida pelos equipamentos ligados à internet - telefones, palms e computadores. Foi o que aconteceu no tradicional Colégio Santo Inácio, do Rio de Janeiro. "Bloqueamos por motivos educativos e de segurança" ${ }^{20}$, explica Eduardo Monteiro, assessor do colégio, à reportagem da Isto é Online. Muitos jovens, por sua vez, carregam certo sentimento de culpa pela adesão incondicional ao novo modo de comunicar-se. Segundo a mesma revista, a universitária Priscilla Piffer, 19 anos, tem por hábito iniciar o bate-papo pelo computador às 13 horas, quando chega da faculdade, e segue on-line até as 23 horas todos os dias. Chega a teclar 18 horas seguidas. "Tentei diminuir o tempo de permanência, mas não consegui”"1 , lamenta a estudante. A jovem reconhece que a mania atrapalhou seu rendimento no último emprego. Foi preciso que o pai a obrigasse a transferir o computador do quarto para a sala de visitas para que ela voltasse a dormir corretamente.

Jovens como Priscilla vêm buscando o auxílio de psicólogos. Para atender à demanda, a PUC-SP acaba de instalar o NPPI - Núcleo de Pesquisa da Psicologia em Informática, um centro que trata dos sintomas do que se denomina Internet Addiction Disorder. Algo parecido com o que ocorre com a dependência de drogas, bebida, jogos de azar etc. ${ }^{22}$. A própria Microsoft assume a liderança entre as empresas do setor que se dirigem aos pais e professores com sugestões
19. <http://www.terra. com.br/istoe/. Acesso em: 26 abr. 2006

20. Ibid.

21. Ibid.

22. MARQUEZI, Dagomir. A Internet virou doença? Info Exame, São Paulo v. 21 , n. 246 , p. 36 , set. 2006. 
sobre como os responsáveis pela educação das novas gerações devem conviver com o mundo da internet ${ }^{23}$.

Diante da apreensão geral, o sistema educativo procura aproximar-se das tecnologias de forma recatada. Tecnologia sim, mas sob controle. Seu uso com parcimônia justifica-se para garantir a performance do professor, melhorando sua didática ou distribuindo conteúdos de maneira mais barata e rápida. Nada que pretenda incentivar o uso indiscriminado do novo aparato tecnológico ou que venha desviar ou alterar o equilíbrio de força na teia das relações no espaço escolar. Em outras palavras, o aluno não estaria autorizado a avançar mais que o professor, mantendo-se intacta, dessa forma, a hierarquia funcional na produção do conhecimento.

\section{O MERGULHO NAS TECNOLOGIAS, SEM TEMORES}

Há educadores que preferem o caminho do risco, o caminho da apropriação. Para eles, não há como deter a tecnologia quando esta assegura a possibilidade de se promover o desenvolvimento da sociabilidade dos educandos. O caminho mais saudável, no caso, é o da convivência com o fenômeno, criando condições para que os jovens transformem-se, eles mesmos, em usuários atentos e críticos: se é verdade que o jovem brasileiro tem sido aquele que mais se identifica com os mecanismos de relacionamento propiciados pela tecnologia digital, cabe à educação apropriar-se do processo, no contexto da nova condição civilizatória. Quanto aos abusos, nada como uma negociação entre os educadores e os educandos para que se encontre o ponto de equilíbrio.

Nessa linha, cabe à educação superar a visão ainda hegemônica de que as TICs - Tecnologias da Informação e da Comunicação sejam exclusivamente instrumentos voltados para ampliar o repertório dos docentes, em suas atividades didáticas. A nova proposta - baseada justamente na manifestação de adesão do jovem brasileiro à capacidade operacional das tecnologias digitais em ampliar os espaços de comunicação - associa o gosto pela experiência on-line à vocação gregária das pessoas, sejam crianças, jovens ou adultos; reconhece-se, dessa forma, o relacionamento virtual como espaço legítimo de produção colaborativa de novas referências para o convívio humano. Trata-se da legitimação do conceito segundo o qual a educação para a convivência onde as pessoas encontram-se ganha importância semelhante à tradicional pedagogia voltada para a aprendizagem de conteúdos, mediada ou não por computadores.

De acordo com a nova perspectiva, o conceito de espaço de entretenimento soma-se ao de superestrada da informação (information superhighway). Na verdade, mais que caminho a ser percorrido, a superestrada representa a praça eletrônica, onde as pessoas têm à disposição um universo incalculável de novos contatos, relações e estímulos, encontrando-se em condições de buscar elementos favo-

23. <http://www.microsoft com/brasil/athome/security/children/kidwebaddict. mspx>. ráveis à reestruturação de suas visões de mundo, influenciando-se mutuamente. No caso, a tecnologia passa a ser definida pelos serviços que é capaz de prestar às necessidades humanas mais imediatas, como o aprofundamento da 
convivência e o intercâmbio intelectual e emocional. Para tanto, como já foi lembrado, um capítulo indispensável nesse processo é a construção de regras de convivência com a máquina, num trabalho que mobilize toda a comunidade educativa.

A educomunicação vê com simpatia a nova postura ${ }^{24}$. Conforme a perspectiva da educomunicação, o ambiente educacional tem sido extremamente favorecido pela criação de comunidades virtuais, uma vez que a busca de informações e os contatos interpessoais propiciados pela rede mundial de computadores auxiliam a cooperação, um dos princípios básicos das mais atualizadas teorias da educação. Importa saber se o que se está constituindo são comunidades conscientes (conscious communities), entendidas como comunidades que valorizam as necessidades pessoais de crescimento e transformação de seus membros, assim como as necessidades básicas do próprio corpo social. Para tanto, é de fundamental importância a valorização desse modelo pelo sistema educativo (ou educomunicativo), posicionando-se o professor como mediador das relações entre seus alunos e a máquina.

Experiências nesse sentido vêm sendo realizadas nos Estados Unidos. Testemunhamos o fenômeno em viagem pelo país, no ano de 2000, confirmando-se o uso criativo da internet para abrir a perspectiva de relacionamento com o mundo por parte das novas gerações num livro de Don Tapiscot denominado Growing up Digital! ${ }^{25}$. O fenômeno da Geração NET, como é chamado, é constituído por adolescentes que, ao contrário de seus pais e avós, acabaram descobrindo que existia um outro mundo para além da fronteira americana. Ampliação do campo de visão e fortalecimento da solidariedade têm sido os frutos imediatos dessas experiências.

No Brasil, recente experiência é desenvolvida pelo Núcleo de Comunicação e Educação da USP junto a dois mil jovens com renda familiar de até um salário mínimo, num programa do Ministério do Trabalho e Emprego, integrado ao projeto Consórcio da Juventude (Embu das Artes, dezembro de 2005 a abril de 2006). O trabalho pedagógico, envolvendo exercícios de práticas comunicativas, produção radiofônica e construção de blogs na internet, possibilitou que tímidos, arredios e muitos adolescentes pobres da periferia desenvolvessem a auto-estima e o mínimo de condições pessoais necessárias para iniciar a luta por uma primeira chance no mundo do trabalho. Como conseqüência, esses jovens adquiriram também a esperança de encontrar um lugar ao sol no mundo dos significados produzidos pela sociedade.

E quanto aos abusos e aos perigos da internet? A escola é o espaço para detectá-los e criar os antídotos, desde que a operação faça-se de forma colaborativa, em processos que envolvam toda a comunidade. Em Embu das Artes, por exemplo, um código de ética para o uso da internet foi a primeira atividade prevista, levando os próprios estudantes a definirem as regras de acesso. O princípio era o seguinte: ou os adolescentes constroem suas próprias referências sobre o que seja ou não adequado, ou simplesmente esquecerão as admoestações dos adultos, mergulhando de coração e alma no novo universo digital, para o bem ou para o mal...
24. Sobre o conceito da educomunicação, ver: SOARES, Ismar de Oliveira. Educomunicação: um campo de mediações. In: Comunicação \& Educação, São Paulo: ECA/USPSegmento, ano VII, n. 19, p. 12-24, set./dez. 2000; e id. Gestão comunicativa e educação: caminhos da educomunicação, In: Comunicação \& Educação, São Paulo: ECA/USP-Segmento, ano VIII, n. 23, p. 16-25, jan./abr. 2002.

25. TAPSCOTT, Don. Growing Up Digital!: the Rise of the Net Generation. New York: Mc-Graw-Hill, 1997. Uma súmula do livro pode ser encontrada em: <http://www.janelanaweb.com/livros/generat2. html> (em inglês) e em $<$ http://www.janelanaweb. com/geracao/dtlivro.html> (em português). 
A redefinição do conceito de comunidade educativa virtual (virtual conscious community) aproxima ainda mais a educação da comunicação. Fica cada vez mais claro que o crescimento da internet e de sua incrível popularidade entre os jovens amplia o ecossistema comunicativo criado pelo ambiente escolar, aumentando as possibilidades de interação. Vivemos em comunidades e buscamos comunidades, e isso somente pode ser feito através da comunicação e do uso de todos os seus meios e linguagens e, no caso das comunidades virtuais, por meio das mídias eletrônicas. O caminho, portanto, propõe sua adoção, com cuidado, mas sem temores.

A liberdade no uso colaborativo dos novos meios de informação vem alcançando alguns resultados relevantes, tais como:

1) A eliminação do temor em relação ao novo. Uma pedagogia de convívio positivo com as tecnologias garante novo sentido à prática educativa.

2) A ampliação das habilidades de comunicação dos membros das comunidades - tanto professores quanto alunos -, transformando educadores e educandos em protagonistas de seus próprios processos de construção coletiva do saber e do conviver.

Enfim, podemos concluir que a tecnologia eletrônica garante leveza e criatividade ao ambiente educacional, sempre que a apropriação de seus recursos e processos dê-se a partir do reconhecimento da potencialidade da comunicação em favorecer a construção permanente de novas alternativas de busca de conhecimento e de convivência. A isto a educomunciação denomina mediação tecnológica nos espaços educativos.

Resumo: Qual é o desafio que os sites de relacionamento, como o Messenger, da Microsoft, e a rede de relacionamentos Orkut, do Google, entre os mais populares, representam para a educação? É possível ignorar a presença desta nova forma de expressão comunicativa? Estas são algumas das questões abordadas neste artigo com base nas pesquisas realizadas pelo Núcleo de Comunicação e Educação da ECA-USP, como a recente experiência desenvolvida junto a dois mil jovens com renda familiar de até um salário mínimo, em Embu das Artes, SP, envolvendo exercícios de práticas comunicativas, produção radiofônica e construção de blogs na internet. É o que a educomunicação denomina mediação tecnológica nos espaços educativos.

Palavras-chave: educomunicação, sites de relacionamento, Orkut, Messenger, Google.
Abstract: What challenge do relationship tools like Microsoft's Messenger and networking sites like Google's Orkut present for education? Is it possible to ignore the presence of this new way of expressing? These are some of the questions asked in this article based on the researches made by the Núcleo de Educomunicação of ECA-USP, as the recent experience developed with 2 thousand youngsters of low income families, involving exercises of communicative practices, radio production and blogs construction. That is what educommunication calls technological mediation in educational spaces.

Keywords: educommunication, relationship sites, Orkut, Messenger, Google. 